\title{
SMART social science? Examining the nature and role of social scientific expertise in institutional design
}

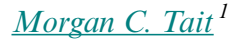

\begin{abstract}
Daniel Bromley argues against Oran Young's FIT model as a basis for environmental governance, on the grounds that humans cannot manage nature and that attempts to do so are based on a scientistic, modernist conceit. At issue is the role of natural and social scientists in adjudicating questions about what we ought to do to close governance gaps and address unsustainable behaviors. If Bromley is right, then the lessons of the American pragmatist tradition recommend against attempts to "fit" social institutions to the natural world. The first objective of this paper is to argue that Bromley's view is not in keeping with the pragmatism of C. S. Peirce and John Dewey, which actually places a high value on natural and social scientific modes of inquiry in the service of social ends. I argue that Young's proposal is in fact a development of the pragmatist idea that social institutions must be fit in the sense of fitness, i.e., resilient and able to navigate uncertainty. Social institutions must also evolve to accommodate the emerging values of the agents who operate within them. The second objective of this paper is to examine the role of social science expertise in the design of social policies. Governance institutions typically rely on the testimony of natural scientists, at least in part, to understand the natural systems they operate within. However, natural systems are also social systems, so it seems pertinent to ask whether there is a role for social systems experts to play in helping to design environmental governance institutions. I argue that social scientists can make a unique contribution as experts on social institutions, and as such, are necessary to bring about a transformation of the unsustainable institutions that are preventing us from achieving stated sustainable development goals.
\end{abstract}

Key Words: American pragmatism; environmental governance; institutional fit; philosophy of science; philosophy of social science; science and policy; sustainable development goals

\section{INTRODUCTION}

In an article in Ecology and Society, Daniel Bromley (2012) argues that the proper role of science in designing environmental governance frameworks has been widely misunderstood. Bromley contends that environmental management is a "modernist conceit," one that continues to hold sway in the contemporary environmental governance literature. According to Bromley, attempts to manage the environment wrongly suppose that human systems can be designed to match or fit with natural systems through effective institutional design. Bromley focuses on Oran Young's (2008a) FIT proposal as paradigmatic of this approach to governance as management, but his argument is more general in scope. Scientific knowledge, according to Bromley, cannot be mobilized to ensure a fit between social institutions and natural systems, as Young's and other similar proposals would suggest. Although science can contribute to the learning process, it cannot tell us what we ought to care about, which is crucial to the design of social institutions.

Young's FIT proposal is paradigmatic of current attitudes toward the role of science in environmental governance. For example, a recent commentary in Nature argues that scientists have an integral role to play in supporting sustainable development goals (SDGs) by "integrating monitoring and evaluating mechanisms into policy-making at all levels" (Lu et al. 2015:433). The authors include social science in their analysis, suggesting that social scientists "should propose what sorts of data on behavior, values and beliefs should be collected and analyzed, how and by whom" ( $\mathrm{Lu}$ et al. 2015:432). Taken out of context, the idea that management regimes should be designed to reflect the realities of the systems they manage seems innocuous, if not an outright truism. However, the guiding principle of the Lu et al. proposal is that policy targets, and by extension, the governance institutions that make it possible to achieve them, should be SMART, i.e., specific, measurable, attainable (and ambitious), relevant, and time-bound (ICSU and ISSC 2015:78). These are lofty goals given the complexity of social processes, their multifaceted relations to natural processes, and the morally contentious task of determining what counts as relevant SDG targets. The relevant tasks obviously cannot be determined a priori but will emerge through social learning processes, experimentation, and adaptation.

This paper has two main goals. First, I argue that institutional development in the sense of FIT is well justified by the contemporary demands of environmental governance. Bromley claims that FIT has its origins in the assumptions of an outmoded modernist worldview. However, regardless of the historical accuracy of Bromley's claim, the real test of concepts like FIT is in their application to contemporary governance challenges. In that setting, proposals like FIT have much to offer. I also criticize Bromley's contention that pragmatist philosophy recommends against institutional design processes such as FIT. Bromley's rejection of "modernist management" could easily be misinterpreted as a skeptical attack on the legitimacy of scientific expertise as such, especially in the realm of policy advice. I do not think this is what Bromley intends, but given the contemporary distrust of science in some quarters, especially as applied to basic (as opposed to industrial) research, it is a danger worth flagging (Munro 2015). It is also not in keeping with the pragmatism of C. S. Peirce and John Dewey, which places a high social value on scientific modes of inquiry. 
The second main objective of this paper is to examine social science expertise as a policy design tool distinct from expertise in the natural sciences. One of the most pressing problems of our time concerns the transformation of existing unsustainable social institutions. Governance institutions rely on the testimony of natural scientists, at least in part, to understand the natural systems they operate within. However, natural systems are also social systems, and so it seems pertinent to ask whether there is a role for social systems experts to play in helping to design environmental governance institutions. If there are such experts, we need to get their advice. A pressing question concerns the suggestion of Lu et al. (2015) that social scientists should collect and analyze "data on behavior, values and beliefs." As the authors observe, there is not currently an institutional analog, for social systems, of the natural science expert who collects data on natural systems to provide rigorous evidence-based policy advice. It is not obvious that social scientists are in a position of epistemic or moral authority to offer SMART advice on social systems, given the irreducibly normative and political dimensions of the social.

Bromley draws upon the American pragmatist tradition, especially Charles Sanders Peirce, to defend what he regards as a more realistic, postmodern account of how knowledge is generated and mobilized in human communities, in contrast to what Holling and Meffe (1996) call the "pathological" management approach. In the broadest terms, pragmatists argue that knowledge allows agents to successfully engage with the world by furnishing tools for action. This is supposedly in contrast to the modernist approach, which in Bromley's view "authorizes an expert to define for us what is out there" and thereby develop blueprints for matching social institutions to it (Bromley 2012:16). In Bromley's view, Peircean pragmatism has important consequences for redressing the "conceit of management" in environmental governance. I hope to show that the acquisition of knowledge in the natural and social sciences can indeed be understood in broadly Peircean terms, as Bromley suggests. However, this Peircean epistemology leads to science that is perfectly objective and up to the task of "informing the formulation of evidence-based targets and indicators, to assessing progress, testing solutions, and identifying emerging risks and opportunities" (ICSU and ISSC 2015:9). There is nothing postmodern about Peircean pragmatism. On the other hand, the suggestion of Lu et al. (2015) that social scientists should collect and analyze "data on behavior, values and beliefs" needs to be unpacked. I will briefly examine some of the legitimate challenges facing any attempt to extend the domain of the scientific advisor qua expert to the social realm.

\section{BROMLEY'S ARGUMENT: MOVING PAST THE CONCEIT OF MANAGEMENT}

Bromley's main argument uses Young's (2008a) FIT proposal as its launching point. Therefore, I begin by summarizing the salient points of that proposal and related research on the problem of institutional fit.

Young distinguishes between organizational reform and institutional arrangements as bases for changes in governance. Institutional arrangements concern the "structure of rights, rules and decision-making procedures" that guide behavior (Young 2008a:15). Institutional arrangements are therefore concerned with the process of establishing norms of evaluation, rather than simply applying preexisting norms to the execution of organizational reform. Young seems to imply that one such norm is institutional fitness: sound institutions should seek to establish a goodness of fit between institutional arrangements and the defining features of the problems they address. This of course assumes that such features can be identified unambiguously and that institutional arrangements can be designed to reflect these features. Effective institutions, according to Young, will "feature the introduction of behavioral mechanisms crafted to address these problems" (Young 2008a:21). A perversion of institutional arrangements will lead to problems of fit between behavioral mechanisms or institutional incentives and defining problem features. Free-rider problems are an institutional example of such perverse incentives. In the context of the anthropocene, as biophysical and social systems are seen to be not only linked but interconnected, the need to design effective institutions to navigate human and environmental interactions is all the more pressing. Institutions not only reflect human values, but also are important causal actors at the scale of global social-ecological systems (Crutzen and Stoermer 2000, Galaz et al. 2008, Young 2008b).

Young also echoes the chorus of recent literature calling for an adaptive approach to institutional design, by emphasizing adaptive (co)management and adaptive governance approaches to institutional learning (Dietz et al. 2003, Olsson et al. 2004, Folke et al. 2005, Berkes et al. 2007, Chaffin et al. 2014). All of these approaches emphasize the multilevel and changing form of governance regimes, the difficulty of control over socialecological systems, the need to navigate uncertainty, and the diversity of values and interests in variable institutional contexts. All also involve an experimental approach to the development of a system of rights and rules. However, there is a scope ambiguity in Young's and other similar proposals: Do they mean to suggest that we should experiment with different systems of rights, rules, and decision-making procedures, including scientific and nonscientific approaches? If so, such proposals threaten to beg the question against those approaches that do not value experimentation as a justification for action, by assuming without argument that they must. Or does Young's FIT proposal mean that we should use the institution of scientific experimentation to address issues of institutional fit? There is textual evidence that the latter interpretation is what Young (2008a) has in mind, because he views the unavailability of controlled experiments in institutional design as a weakness in the adaptive management approach. This seems to presume, rather than establish, an institutional framework of evaluation based on controlled experimentation. Young does not address this ambiguity directly, but it is clear that he takes experimentation to be a sacrosanct element of any institutional decision-making process.

Bromley takes issue with Young's broadly scientistic proposal, though not with the invocation of experimentation, on the grounds that it presumes that the environment can be managed for human ends. It is possible to tease apart three related assumptions that Bromley regards as problematic in Young's proposal: (1) that knowledge acquisition in the sciences or other fields leads to an objective representation of the systems the knowledge is about; (2) that such knowledge can be used to match up social systems with natural systems, and that this should be the goal of institutional design; and (3) that experts and 
knowledge generators can be tasked with designing, implementing, and advising processes of institutional fit in general. I will briefly discuss each of these assumptions and why Bromley regards them as problematic before evaluating Bromley's argument.

The first point Bromley raises concerns the nature of knowledge, scientific or otherwise. At first blush, the problem appears to be purely philosophical: Is knowledge acquisition fundamentally an exercise in passive observation, or is it rather an activity or interaction with the knowable, what Bromley calls a process of "active discernment"? According to Bromley's diagnosis, the FIT proposal assumes that knowledge is representational in character, and so it assumes that the task of institutional design experts is to fit together two authentic representations: one of the social system and the other of the natural system to be fitted to it. Bromley suggests that this representational view is incorrect, and that knowledge must be viewed instead as a process of active engagement with systems of interest. Our understanding of the world is based on the sum of its effects on us according to Bromley, and these effects emerge through a process of active discernment rather than through passive observation. Hence, knowledge is a process of learning about what is important to agents or decision makers who acquire and use the knowledge, through a process of discernment. It is to be hoped that this discernment leads to sufficient convergence in belief across different agents over time to allow for institutionalized cooperation. However, because there can be no accurate and final representation of nature, says Bromley, there can be no question of designing governance institutions to reflect that representation.

This leads to the second problematic assumption of FIT: that social systems and natural systems can be matched. Here Bromley points out that policies are not designed in a vacuum. Rather, we have to act before we can really know what we want, because it is through interaction that nature reveals itself to us through its various effects, and the process of learning about nature causes the social system to evolve, precluding any matching of the natural to preexisting social values in the sense of FIT. Put simply, we don't know what Young's defining features of natural systems are until we probe them, and we can't do this without evolving the social institutions that do the probing. Furthermore, "defining features" are morally salient features, and we can't know what is important to us until we are confronted with a choice to act in some manner. As social institutions change, so do priorities. It is therefore a mistake to think that describing natural and social systems can be defined as a separate activity from evaluating their social significance.

This leads to Bromley's third claim: that FIT wrongly assumes that experts and knowledge generators can be tasked with designing, implementing, and advising processes of institutional fit in general. Scientists can contribute to the learning process of working out our relationship with nature, but they cannot "produce truth about what it would be better to do" (Bromley 2012:14). Whatever technical acumen science may possess, the process of working out our priorities and values, the relevant implementation goals, or the defining features of the systems we engage with is essentially a political process rather than a technical one. Designing an institutional blueprint puts the cart before the horse because we won't know what it is we need until we're in a position to need it.

\section{REFLECTIONS ON BROMLEY'S ARGUMENT}

Bromley raises some provocative philosophical challenges for governance frameworks such as FIT. However, I think many of these challenges misconstrue the purpose of FIT and other modernist governance proposals. Whether one adopts a representationalist or a pragmatist epistemology, knowledge is distinguished from other kinds of belief on the basis of processes of justification. Knowledge serves an essential social function: to guide action. Bromley, echoing C. S. Peirce, does not deny that convergence in belief is possible or desirable, or that good reasons for action must always be given if we are to trust in expert recommendations. However, Bromley seems to miss the main point of Peirce's convergence thesis: Different agents will converge in their beliefs provided that they have good reasons for adjusting their beliefs in light of new evidence. For example, in What Pragatism Is Peirce writes:

Just as conduct controlled by ethical reason tends toward
fixing certain habits of conduct, the nature of
which...does not depend on any accidental circumstances,
and in that sense may be said to be destined; so, thought
controlled by a rational experimental logic, tends to the
fixation of certain opinions, equally destined, the nature
of which will be the same in the end, however the
perversity of thought of whole generations may cause the
postponement of the ultimate fixation. If this be so,
then... according to the adopted definition of "real," the
state of things which will be believed in that ultimate
opinion is real. (Peirce 1962:148)

The existence of expert (near) consensus or "fixation of opinions" is evidence of the legitimacy and generality of the norms used to produce it. At a minimum, science is characterized by the systematic collection of data and the attempt to rigorously analyze and interpret it, and to justify these attempts in the community of scientists. This is a formalized process that is not qualitatively different, according to Peirce, from justification of belief in everyday life. Such justification is always a social process, and convergence occurs when different agents apply the same "rational experimental logic" to the analysis of experience. This last point is the most interesting from a philosophical point of view because it implies that science is a highly developed exercise of everyday habits of conduct.

How do opinions become fixed, and what justifies their fixation? Peirce does not deny that convergent belief is a representation of something external to the belief itself. Rather, he regards the assertion as meaningless. Whether and to what extent convergent beliefs correspond to external reality is not a question whose answer has practical (experiential) consequences. For example, if I assert that a coin has the property of being fair, I am giving voice to an expectation. So I expect that if I toss the coin multiple times, the frequency of heads and tails will be roughly equal. Furthermore, any rational agent can experiment with the same coin by tossing it, and thereby come to believe (converge on the belief) that it is fair. However, fairness is not what Peirce calls a latent property of the coin; it is a way of characterizing the expectations of rational agents who interact with it, the fixation of opinion regarding their possible experiences with the coin. To say that fairness is a property of the coin is just shorthand for the publicly accessible, reasonable expectation that it will behave in a certain way, and nothing more. 
This Peircean picture of knowledge as a set of justified, provisional expectations regarding future experience is all that is needed for SMART institutional governance. Such governance will involve the integration of monitoring and evaluative frameworks into institutionalized decision-making processes. Construed as an institution of knowledge generation, science certainly has an important role to play in institutional design, because scientists are in a position to carefully examine, test, and monitor our expectations about natural and social systems.

This is obviously not to suggest that science alone can offer solutions for sustainable environmental governance. Even if the acquisition of scientific knowledge is governed by rational and reasonable epistemic norms, and even if the expectations furnished by scientific research are credible, it does not follow that scientists are in a position to tell us what it would be better to do, or which knowledge gaps are most in need of being filled. However, scientists can point out problems that might never have occurred to ordinary citizens, and they can offer technical advice about how to address these problems through effective institutional design. This is why it is crucial that we develop institutions that promote scientific research as well as an institutional role for scientists as policy advisors. Proposals like FIT do not, as Bromley suggests, erroneously suppose that we can know what we need to do a priori. On the contrary, the fact that we can't know what lies ahead is all the more reason to develop institutional governance systems capable of reacting to and even flourishing in novelty. Such institutions must be fit in the sense of fitness, i.e., resilient and able to navigate uncertainty. They must also respect existing, and respond to emerging, values of the agents who operate within them.

These considerations lead to an important question that is not addressed in Bromley's article, namely, whether and to what extent social scientists, as distinct from natural scientists, have a specific role to play in the design, monitoring, and implementation of governance institutions. As the recent literature on institutional fit and institutional diagnostics in the context of the anthropocene has emphasized, natural and social systems cannot be meaningfully decoupled, all natural systems are also social systems, and transitioning toward sustainability is an inescapably social process (Galaz et al. 2008, Young 2008b). This implies that natural systems expertise is not sufficient, from a governance perspective, given the ontology of the social-ecological systems that such expertise is about, namely, dynamically interconnected social-ecological systems (Breitmeier et al. 2006). It would seem that if we are to provide a scientific basis for strategically influencing social-ecological systems and processes, we require the resources of the social sciences, and these must somehow be made to cooperate with the natural sciences in any sustainable institutional governance framework. However, expertise in the social sciences is contested in a way that natural scientific expertise is not. There is no unified social scientific methodology, and perhaps this is not a deficiency given the unique subject matter of these sciences. However, this lack of consensus presents epistemological, methodological, and political challenges for social scientists as policy advisors.

\section{THE NATURAL AND SOCIAL SCIENCES, AND SMART SUSTAINABILITY}

If what has been argued here is correct, then Bromley's analysis of institutional FIT somewhat misses the mark. The issue is not that knowledge in the sciences is infected by a modernist, representationalist bias. Even with a Peircean pragmatist picture of knowledge as a basis for action, there is an important role for scientists to play in the development and justification of environmental governance institutions. Bromley's argument that natural systems and social institutions cannot be matched is open to the obvious rejoinder that natural and social systems are inextricably linked. Because human activity influences and is influenced by natural systems, it follows that any attempt to offer scientific policy advice that ignores the social element in socialecological systems is incomplete. This social element obviously includes social institutions and meaningful attempts to consciously design them such as FIT. Bromley's claim that scientists cannot offer advice about what it would be better to do misses the point. What we need from the social as well as the natural sciences is input into the design of effective governance institutions capable of being the instruments of normative policy, whatever that policy may be. This must include the best possible advice from social scientists about the nature and function of social institutions and the drivers of effective social change. Ironically, Bromley's proposal amounts to a new kind of institutional advice of just this kind, based on his own theory of social institutions, because he defends the view that any proposed institutional mechanism must be "good to think with," in other words, useful for interacting with other natural and social phenomena (Bromley 2012:19).

Any proposal that defends the view that social scientists have a role to play in institutional design must confront the fact that social scientists do not have the same epistemic authority as their natural science counterparts. In contrast to the natural sciences, there is relatively little consensus among social scientists regarding methodology, for a variety of reasons (Gouldner 1970, Gulbenkian Commission on the Restructuring of the Social Sciences 1996, Goertz and Starr 2003, Tilly 2003, Sewell 2005, Little 2009, Knight 2009). This lack of minimal consensus is unfortunate from a political point of view, because if social science-informed policy recommendations are to be SMART (i. e, specific, measurable, attainable [and ambitious], relevant, and time-bound), and if social scientists are to provide "data on behavior, values and beliefs," a frank conversation is required about what social phenomena are relevant, and how or even if they can be rigorously observed. The implicit argument in proposals like those of Lu et al. (2015) and the United Nations SDGs is that to design effective and legitimate institutions, we need an adequate representation of social phenomena (or, in Peircean terms, reasonable expectations about them), and that no one is better positioned to provide the data than social scientists. Social science arguably has a role to play in answering two distinct questions: "what do we want?" through direct empirical research such as surveys and "how do we get there?" through theories of change justified by empirical evidence. However, legitimizing the role of social science in answering either of these questions is no easy task, because it requires a rigorous defense of empirical social scientific methodology, or perhaps methodologies. The stakes for institutional development are high, and the standards of evidence must be correspondingly high.

What makes the social sciences "scientific," such that policy designers should heed their advice? One thing that virtually all writers on this large and divisive topic have agreed upon is that the natural sciences do not provide a straightforward model for 
the social sciences, although both seek to systematically investigate empirical phenomena. Nevertheless, Daniel Little (2009) offers an interesting proposal that has the potential to shed some light on the prospects for SMART institutionalized social science.

Little observes that much work in the social sciences relies upon causal explanations, even if these explanations lack the complete generality of explanations in physics (Tilly 2003, George and Bennett 2005). The assumption that causal mechanisms exist is compatible with the nonexistence of causal covering laws. In other words, even if you don't believe that there are social laws, you may still believe in social mechanisms. These mechanisms may not be amenable to laboratory observation, and they are historical in the sense that they are not generally testable by means of repeatable experiments. However, if they exist, such mechanisms might still inform the development of legitimate institutions by providing an ontological basis for the empirical analysis of social patterns and processes.

Little (2009) does not hold out much hope for prediction in the social sciences, on the grounds that social regularities are derivative from the agents who instantiate them, and individuals are not homogeneous enough to predict their behavior. If prediction requires regularity in the phenomena to be predicted, the heterogeneity of actors in the social realm will limit our capacity to draw general predictive conclusions. This problem is exemplified in the context of resource management "panacea traps," when managers falsely assume that the preferences and priorities of most resource managers are the same (Ostrom et al. 2007). However, limitations on predictive power are hardly unique to social science and do not necessarily tell against the legitimacy of a theoretical framework. Unpredictability is an unavoidable consequence of modeling complex systems in any domain. By the standards of Newtonian physics, evolutionary biology also fails to reliably predict specific phenomena, but retains its epistemic authority on grounds of explanatory unification and the capacity to predict general functional trends like fitness (Scriven 1959, Lieberson and Lynn 2002).

Given their complexity, one might wonder whether the causal mechanisms to be found among social phenomena are sufficiently regular to lend scientific credibility to institutional design stemming from social scientific research. If social science hypotheses are testable, and social phenomena exhibit sufficient regularity to warrant the attribution of causal mechanisms, then social science expertise can be marshaled for institutional development. Institutions that respond to real causal mechanisms in the social realm are more likely to succeed. Furthermore, the degree of regularity exhibited by any social phenomenon is testable, through case study methodology, comparative study, statistical analysis, qualitative analysis, and the application of social theories to all of these methodological tools. We can also test the extent to which a given phenomenon can be viewed as an instance of a certain class of phenomena using these methods. If we have sufficient grounds to be causal realists in the social realm, or if we believe that there are genuine social causal mechanisms, then knowledge of these mechanisms will be indispensible to institutional development. This conclusion is as compelling for a pragmatist like Bromley as it is for a modernist, because it is causal mechanisms that produce effects on the agents who make up social institutions, as well as the natural systems they interact with.

\section{CONCLUSION}

I have argued that Daniel Bromley's criticism of "modernist" environmental governance proposals misses the mark. The essential point of proposals such as that of Young (2008a) is that governance institutions must be a good fit for the systems they operate within, and that a business-as-usual approach to environmental governance may have disastrous consequences. Bromley's pragmatist epistemological approach, which he erroneously sets at odds with the modernism he criticizes, does not successfully undermine this basic point. The invocation of pragmatist epistemology and social theory actually serves to strengthen the rational basis for proposals such as FIT and the United Nations SDGs rather than diminish them.

Nevertheless, a frank conversation is needed about the role of social experts, if they exist, in policy development. Resistance to this idea may be partly philosophical, because it is seen by some to lead to top-down social engineering schemes, colonialism, or outmoded positivist scientism (Howe 2004, Maxwell 2004). Nevertheless, whether there are social causal mechanisms, and whether they are sufficiently regular to inform institutional development, is a crucial governance question that needs to be answered, and requires the input of the social sciences. Building capacity to provide such input must be a goal of institutional development regardless of our immediate attitude toward social ontology. The idea that technical work and policy development can be treated separately, or that policy development and justification are not in part a technical problem requiring input from the social sciences, is as outmoded as the idea that social systems can be understood separately from natural systems. This is one of the main lessons of American pragmatism, exemplified especially in the work of John Dewey:

\section{Operational thinking needs to be applied to the judgment of values just as it has now finally been applied in conceptions of physical objects. Experimental empiricism in the field of ideas of good and bad is demanded to meet the conditions of the present situation. (Dewey 1962:348)}

Dewey was writing in 1929 , but the point remains prescient today. Value experimentalism also seems to be a corollary of the observation that social systems and ecological systems cannot be decoupled. I take this entanglement of the social and the natural to be a basic assumption of proposals such as FIT. If there are natural systems experts, we would do well to ask if there are also social systems experts, and if there are, we need to get their advice. Social systems experts are not just social scientists but also policy advisors with social science expertise, capable of providing empirical insight into existing social values and the social mechanisms that embody them.

Responses to this article can be read online at: http://www.ecologyandsociety.org/issues/responses. $\mathrm{php} / 8472$ 


\section{Acknowledgments:}

I would like to thank Meaghan Eastwood and Daniel McCarthy, and an anonymous reviewer for helpful comments and discussion of earlier drafts of this manuscript.

\section{LITERATURE CITED}

Berkes, F., D. R. Armitage, and N. Doubleday. 2007. Adaptive comanagement: collaboration, learning, and multi-level governance. UBC Press, Vancouver, British Columbia, Canada.

Breitmeier, H., O. R. Young, and M. Zürn. 2006. Analyzing international environmental regimes: from case study to database. MIT Press, Cambridge, Massachusetts, USA.

Bromley, D.W. 2012. Environmental governance as stochastic belief updating: crafting rules to live by. Ecology and Society 17 (3):14. http://dx.doi.org/10.5751/ES-04774-170314

Chaffin, B. C., H. Gosnell, and B. A. Cosens. 2014. A decade of adaptive governance scholarship: synthesis and future directions. Ecology and Society 19(3):56. http://dx.doi.org/10.5751/ ES-06824-190356

Crutzen, P. K., and E. F. Stoermer. 2000. The 'Anthropocene'. IGBP Newsletter 41:17.

Dewey, J. 1962. The construction of good. Pages 346-366 in W. Barrett and H. D. Aiken, editors. Philosophy in the 20th century. Random House, New York, New York, USA.

Dietz, T., E. Ostrom, and P. C. Stern. 2003. The struggle to govern the commons. Science 302(5652):1907-1912. http://dx.doi. org/10.1126/science.1091015

Folke, C., T. Hahn, P. Olsson, and J. Norberg. 2005. Adaptive governance of social-ecological systems. Annual Review of Environment and Resources 30:441-473. http://dx.doi.org/10.1146/ annurev.energy.30.050504.144511

Galaz, V., P. Olsson, T. Hahn, C. Folke, and U. Svedin. 2008. The problem of fit among biophysical systems, environmental and resource regimes, and broader governance systems: insights and emerging challenges. Pages 147-186 in O. R. Young, L. A. King, and $\mathrm{H}$. Schroeder, editors. Institutions and environmental change: principal findings, applications, and research frontiers. MIT Press, Cambridge, Massachusetts, USA. http://dx.doi.org/10.7551/ mitpress/9780262240574.003.0005

George, A. L., and A. Bennett. 2005. Case studies and theory development in the social sciences: BCSIA studies in international security. MIT Press, Cambridge, Massachusetts, USA.

Goertz, G., and H. Starr, editors. 2003. Necessary conditions: theory, methodology, and applications. Rowman and Littlefield, Boulder, Colorado, USA.

Gouldner, A. W. 1970. The coming crisis of Western sociology. Basic Books, New York, New York, USA.

Gulbenkian Commision on the Restructuring of the Social Sciences. 1996. Open the social sciences: report of the Gulbenkian Commission on the restructing of the social sciences. Stanford University Press, Stanford, California, USA.
Holling, C. F., and G. K. Meffe. 1996. Command and control and the pathology of natural resource management. Conservation Biology 10(2):328-337. http://dx.doi.org/10.1046/ j.1523-1739.1996.10020328.x

Howe, K. R. 2004. A critique of experimentalism. Qualitative Inquiry 5:42-61. http://dx.doi.org/10.1177/1077800403259491

International Council for Science and International Social Science Council (ICSU and ISSC). 2015. Review of targets for the sustainable development goals: the science perspective. ICSU, Paris, France.

Knight, J. 2009. Comment: causal mechanisms and generalizations. Pages 179-184 in C. Mantzavinos, editor. Philosophy of the social sciences: philosophical theory and scientific practice. Cambridge University Press, New York, New York, USA. http://dx.doi.org/10.1017/CBO9780511812880.015

Lieberson, S., and F. B. Lynn. 2002. Barking up the wrong branch: scientific alternatives to the current model of sociological science. Annual Review of Sociology 28(1):1-19. http://dx.doi.org/10.1146/ annurev.soc. 28.110601 .141122

Little, D. 2009. The heterogeneous social: new thinking about the foundations of the social sciences. Pages 154-178 in C. Mantzavinos, editor. Philosophy of the social sciences: philosophical theory and scientific practice. Cambridge University Press, New York, New York, USA. http://dx.doi.org/10.1017/ cbo9780511812880.014

Lu, Y., N. Nakicenovic, M. Visbeck, and A.-S. Stevance. 2015. Five priorities for the UN sustainable development goals. Nature 520(7548):432-433. http://dx.doi.org/10.1038/520432a

Maxwell, J. A. 2004. Reemergent scientism, postmodernism, and dialogue across differences. Qualitative Inquiry 10:35-41. http:// dx.doi.org/10.1177/1077800403259492

Munro, M. 2015. Canadian budget pushes applied research. Nature 520(7549):595-596. http://dx.doi.org/10.1038/nature.2015.17305

Olsson, P., C. Folke, and F. Berkes. 2004. Adaptive comanagement for building resilience in social-ecological systems. Environmental Management 34:75-90. http://dx.doi.org/10.1007/s00267-003-0101-7

Ostrom, E., M. A. Janssen, and J. M. Anderies. 2007. Going beyond panaceas. Proceedings of the National Academy of Sciences of the United States of America 104(39):15176-15178. http://dx.doi.org/10.1073/pnas.0701886104

Peirce, C. S. 1962. What pragmatism is [1905]. Pages 136-151 in W. Barrett and H. D. Aiken, editors. Philosophy in the 20th century. Random House, New York, New York, USA. http://dx.doi. org/10.5840/monist190515230

Scriven, M. 1959. Explanation and prediction in evolutionary theory. Science 130:477-482. http://dx.doi.org/10.1126/ science. 130.3374 .477

Sewell, W. H., Jr. 2005. Logics of history: social theory and and social transformation. Chicago Studies in Practices of Meaning. University of Chicago Press, Chicago, Illinois, USA. http://dx. doi.org/10.7208/chicago/9780226749198.001.0001

Tilly, C. 2003. The politics of collective violence. Cambridge Studies in Contentious Politics. Cambridge University Press, Cambridge, UK. http://dx.doi.org/10.1017/CBO9780511819131 
Young, O. R. 2008a. The architecture of global environmental governance: bringing science to bear on policy. Global Environmental Politics 8(1):14-32. http://dx.doi.org/10.1162/ glep.2008.8.1.14

Young, O. R. 2008b. Building regimes for socioecological systems: institutional diagnostics. Pages 115-144 in O. R. Young, L. A. King, and H. Schroeder, editors. Institutions and environmental change: principalfindings, applications, and research frontiers. MIT Press, Cambridge, Massachusetts, USA. http://dx.doi.org/10.7551/ mitpress/9780262240574.003.0004 